\title{
LA POLÍTICA EN LAS TRAMAS EDUCATIVAS
}

de Bernardo Carrizo y Juan Cruz Giménez (coords.), Paraná, Fundación Editorial La Hendija, 2017, 410 pp.

EVA MARA PETITTI

CONICET-Universidad Nacional de Entre Ríos

La politica en las tramas educativas es una obra colectiva compilada por Bernardo Carrizo y Juan Cruz Giménez, investigadores y docentes de la Facultad de Humanidades y Ciencias de la Universidad Nacional del Litoral. A lo largo de sus páginas, pone de manifiesto las posibilidades de indagar la política y lo político en el campo educativo, así como de escoger la dimensión política para explorar la educación a lo largo del periodo que transcurre entre finales del siglo XIX y principios del xxi. En este sentido se propone contribuir tanto a la historia política tomando la educación como eje vertebrador, como a la historia de la educación articulándose a través de la política. Como libro de historia política, describe las tensiones entre el oficialismo y la oposición, las disputas entre facciones, entre laicismo y catolicismo, entre conservadu- rismo y liberalismo y se pregunta por las transiciones, por las continuidades y las rupturas en las diferentes gestiones. En tanto libro de historia de la educación, aborda la enseñanza en sus distintos niveles a través de los proyectos educativos, la legislación, los planes de estudio, los libros de texto, los discursos, las corrientes pedagógicas, las instituciones y el gremialismo docente.

Los quince trabajos reunidos en esta compilación tienen el mérito de ilustrar como las tramas que se tejen a nivel nacional, provincial y local, en algunas ocasiones, se acoplan y en otras se superponen. Siguiendo el legado de Darío Macor, con quienes los coordinadores de la obra se formaron, y sus aportes al conocimiento de la historia política argentina del siglo $\mathrm{xx}$, este trabajo constituye una contribución a los estudios regionales. La provincia 
objeto de análisis es Santa Fe y dentro de la misma se particulariza en la localidad de Coronda. Las tres dimensiones se ven conjugadas de diversas maneras según los capítulos. En algunos se aborda Santa Fe en cuanto modelo/desviación de un caso nacional, en ciertos capítulos la provincia constituye un punto de observación de la realidad nacional, mientras que otros reconstruyen una historia local desde una perspectiva micro analítica en diálogo con el ámbito provincial y nacional.

$\mathrm{Si}$ en un primer momento el emprendimiento surgió como la posibilidad de reeditar un libo anterior, finalmente dio lugar a un resultado muy diferente, que tiene entre sus sedimentos los frutos de aquel trabajo titulado Auroras en Provincia: proyectos educativos y discursos pedagógicos en la formación docente santafesina (Igog2009), que reunía ocho trabajos organizados en un orden temporal progresivo.

La obra está organizada como un tríptico. Tres partes, que implican recorridos paralelos que se entrecruzan y retroalimentan. La primera trata sobre los proyectos educativos y escenarios políticos en tensión. Los capítulos que la componen están ordenados cronológicamente. El primero estudia el proyecto de la «escuela nueva» en tensión con los años conservadores a partir de la gestión de Amanda Arias de Clotet como directora de la Escuela Normal de Coronda. El segundo indaga el proyecto del peronismo en la tensión entre democratizar y adoctrinar. El tercero, se centra en los años de post peronismo, en la tensión entre el proyecto de enseñanza laica y el de enseñanza libre. El cuarto, aborda el proyecto de la dictadura y la desaparición de las luchas en el campo, producto de la neutralización de las diferencias. El último de esta primera parte, examina el proyecto de la transición democrática, cuando la inestabilidad y la incertidumbre reemplazaron las tensiones. La segunda parte discurre sobre las batallas educativas en la construcción de diferentes identidades colectivas. Aquí el primer capítulo analiza las luchas en torno a la laicización de la educación entre una sociedad tradicional, que hundía raíces en el pasado colonial y católico, y las provenientes de la modernización liberal, que se reflejaron en la creación de las instituciones educativas que impulsó el laicismo. El segundo capítulo parte de un análisis de los certámenes Premio Patria de la Escuela Normal de Coronda, como producto de la preocupación por la identidad nacional impugnada por el aluvión inmigratorio, abordando las disputas en torno a la nacionalización en el contexto del post Centenario de i9io. El tercero, estudia las batallas por neutralizar la acción política en la educación, partiendo de la pregunta acerca de por qué permanecen veladas las influencias de la dictadura en el sistema educativo y se propone profundizar en la violencia sistemática so- 
bre las instituciones escolares. El cuarto se centra en las batallas por remover los cimientos del sistema educativo durante la reforma educativa de los años 1990 a través del análisis de los debates respecto de los sentidos de la reforma y su impacto en las instituciones, que abrieron las experiencias curriculares ensayadas. El último capítulo de esta segunda parte, describe las disputas por promover una identidad anarquista a través de tres experiencias de la educación santafesina: los anarquistas de fines del xix y principios del xx, las hermanas Cossettini y Rubén Naranjo en la Biblioteca Constancio Vigil. El autor del capítulo señala una continuidad difusa aunque persistente, al estilo de un mapa libertario que fue variando acorde a los sucesivos momentos históricos.

La tercera parte, se ocupa de los instrumentos prescriptivos y las instituciones educativas, haciendo hincapié en la presencia y ausencia de legislación escolar. El primer capítulo se pregunta por los proyectos infructuosos del radicalismo entre 1912 y 1916 para sancionar una ley de educación laica, ya que la entonces vigente desde i886 establecía la educación religiosa en horario de clase. El segundo capítulo analiza la creación de institutos de formación de profesores para el nivel secundario en Santa Fe y profundiza en el Instituto Superior de Profesorado de Coronda. El tercero estudia la dificultad que conllevó la creación de instrumentos prescriptivos para regular los contenidos en el nivel inicial en Santa Fe, donde no existió un diseño curricular vigente hasta la década de 1990, centrándose principalmente en el contexto de la transición democrática. El cuarto capítulo de esta última parte también se preocupa por el periodo transicional, esta vez a través de los Planes de Estudio en el profesorado de Historia. Finalmente el capítulo cinco indaga las dificultades de sancionar una ley de educación provincial durante siete décadas. La Ley que regulaba el campo educativo provincial había sido sancionada en 1886, reformada en 1949 y derogada y suspendida en 1956.

Finalmente, el epílogo ordena el texto, tanto a nivel conceptual como empírico. Por un lado, nos habla de Pierre Rosanvallon y de Pierre Bourdieu, que son centrales en las ideas que atraviesan el libro. Una concepción amplia de «la política/lo político" y el entendimiento de la educación como un campo de disputas. Por otro lado, ordena cronológicamente las interrelaciones entre el Estado, la política y lo político a lo largo del periodo abordado. En cuanto al título de la obra, el mismo tiene que ver no sólo con el contenido sino también con la forma. En relación a lo primero se entiende la trama en los términos analíticos que Pierre Bourdieu define al campo, es decir como una «red o configuración de relaciones objetivas entre posiciones». Así el campo educati- 
vo es analizado como espacio privilegia- un camino abierto para elegir entre las disdo donde se libraron combates políticos. tintas posibilidades de lectura, se presenta Ahora bien, además del interés que pre- como una subversión desde la forma. Así senta desde el punto de vista temático, la como Jacques Rancière propone otra retrama aparece indicando las posibles for- lación maestro-alumno, los autores del limas del contenido. Tal como adelantan bro plantean otra relación autor-lector. En en la introducción a través de una cita de suma, esta obra ofrece a este último una Humberto Eco, los coordinadores pro- mirada de conjunto de las relaciones entre ponen una lectura diferente a la que ellos política y educación desde finales de siglo realizaron al organizar los capítulos. A no xIx hasta comienzos del Xxi, tanto a nivel tener un itinerario recto y otorgar al lector local, como provincial y nacional. 